\title{
Mn-MCM-41 Türü Katalizörler ile Model Atıksulardan Fenol Giderimi
}

\author{
Yeşim Güçbilmez $^{1 *}$, Muayyed Ammar ${ }^{2}$ \\ 1* Eskişehir Teknik Üniversitesi, Mühendislik Fakültesi, Kimya Mühendisliği Bölümü, Eskişehir, Türkiye, (ORCID: 0000-0003-1430-6484), \\ ygucbilmez@eskisehir.edu.tr \\ ${ }^{2}$ Eskişehir Teknik Üniversitesi, Mühendislik Fakültesi, Kimya Mühendisliği Bölümü, Eskişehir, Türkiye (ORCID: 0000-0001-5280-0243), \\ moaayyad.amar1995@gmail.com \\ (International Conference on Design, Research and Development (RDCONF) 2021 - 15-18 December 2021)
}

(DOI: 10.31590/ejosat.1045523)

ATIF/REFERENCE: Güçbilmez, Y., Ammar, M. (2021). Mn-MCM-41 Türü Katalizörler ile Model Atıksulardan Fenol Giderimi. Avrupa Bilim ve Teknoloji Dergisi, (32), 1113-1120.

Öz

$\mathrm{Bu}$ çalışma kapsamında farklı Mn/Si molar oranlarında, Mn katkılı MCM-41 katalizörleri sentezlenmiş ve katalizörlerin karakterizasyonu, XRD, BET, SEM, EDS ve parçacık boyut analizi metotları kullanılarak yapılmıştır. Katalizörlerin aktiviteleri, hidrojen peroksit katkılı yaş katalitik oksidasyon ile model atık sulardan fenol giderimi tepkimesinde test edilmiştir. XRD ve BET sonuçları, saf silikat formdaki MCM-41 destek malzemesinin istenilen altıgen gözenekli yapıda olduğunu, manganez metali eklendiğinde ise kristal yapının bozularak amorf yapıya dönüştüğünü, gözeneklerin kısmen bloke olması nedeniyle de BET yüzey alanlarının önemli ölçüde azaldığını göstermiştir. Fenol giderim reaksiyonları, laboratuar ortamında hazırlanan 50 ppm'lik fenol çözeltisi kullanılarak, 25,40 ve $60^{\circ} \mathrm{C}$ 'de, 6,0 olarak ölçülen başlangıç pH'sında ve kesikli reaktörde yürütülmüştür. Deney sonuçları, optimum metal yüklemesinin $\mathrm{Mn} / \mathrm{Si}$ molar oranı 0,06 olduğunda gerçekleştiğini göstermiştir. Reaksiyon bulguları incelendiğinde, sıcaklıkla birlikte fenol gideriminin arttığı görülmüştür. Buna ek olarak, atmosferik basınç ve çalışılan farklı sıcaklıklarda, katalizör yapısına metal eklenmesiyle birlikte fenol gideriminin, saf silika yapısındaki MCM-41'e oranla, Mn-MCM-41 katalizörleri için, \%4.6-\%14.4 aralığında arttığı görülmüştür. Optimum reaksiyon koşulları, atmosferik basınç, $60^{\circ} \mathrm{C}, 0,06 \mathrm{Mn} / \mathrm{Si}$ molar oranı olarak tespit edilmiş ve bu koşullarda \%56 fenol giderimi elde edilmiştir. Ilımlı tepkime koşullarında $\left(60^{\circ} \mathrm{C}\right.$ ve atmosferik basınç), az miktarda metal ve az miktarda katalizör kullanarak (Mn/Si molar oranı 0,060, katalizör miktarı1,0 g/L), Mn-MCM-41 katalizörleri ile orta derece konsantre model atıksulardan optimum \%56 fenol giderimi elde edilmesinin literatüre önemli bir katkı sağlayacağ 1 düşünülmektedir.

\section{Phenol Removal From Model Waste Waters by Mn-MCM-41 Type Catalysts}

\begin{abstract}
In this study, Mn-incorporated MCM-41 catalysts with different Mn/Si molar ratios were synthesised and the characterisation of the catalysts was carried out by using XRD, BET, SEM, EDS and particle size analysis methods. The activities of the catalysts were tested in the phenol removal reaction from model solutions using the wet catalytic oxidation with hydrogen peroxide. XRD and BET results showed that the MCM-41 support material in the pure silicate form had the desired hexagonal porous structure but upon addition of the manganese metal, the crystal structure deteriorated becoming amorphous and the surface areas reduced significantly due to the partial blocking of the pores. Phenol removal reactions were carried out using a 50 ppm phenol solution prepared in the laboratory at 25,40 and $60^{\circ} \mathrm{C}$, at an initial $\mathrm{pH}$ value of 6.0 in a batch reactor. The experimental results depicted that the optimum metal
\end{abstract}

\footnotetext{
*Sorumlu Yazar: ygucbilmez@eskisehir.edu.tr
} 
loading occurred at a $\mathrm{Mn} / \mathrm{Si}$ molar ratio of 0.06 . Investigation of the reaction results showed that phenol removal increased with temperature. In addition, at atmospheric pressure and at the studied different temperatures, with the addition of the metal to the MCM41 structure, the phenol removal percentage increased in the range of 4.6\%-14.4\% for Mn-MCM-41 catalysts, compared to the purely siliceous MCM-41. Optimum reaction conditions were determined as $60^{\circ} \mathrm{C}$, atmospheric pressure, $0.06 \mathrm{Mn} / \mathrm{Si}$ molar ratio, and $56 \%$ phenol removal was obtained under these conditions. Obtaining an optimum $56 \%$ phenol removal from moderately concentrated model waste waters with Mn-MCM-41 catalysts by using a small amount of metal and small amount of catalyst (Mn/Si molar ratio 0.060 , catalyst amount $1.0 \mathrm{~g} / \mathrm{L})$ under moderate reaction conditions $\left(60^{\circ} \mathrm{C}\right.$ and atmospheric pressure $)$, is thought to make an important contribution to the literature.

Keywords: Mn-MCM-41, Phenol, Wastewater.

\section{Giriş}

Fenol $\mathrm{C}_{6} \mathrm{H}_{5} \mathrm{OH}$ kimyasal formülüne sahip, en zehirli 129 kimyasal listesinde yer alan aromatik bir alkoldür. Fenol, sularda ppm mertebesinde olduğunda dahi klorlanma esnasında belirgin tat ve koku değişikliğine neden olduğu için insan sağlığ açısından son derece zararlı bir maddedir [1-4] ve atıksulardan giderimi büyük önem taşımaktadır.

Fenole pek çok endüstride hammadde ya da aramadde olarak rastlamak mümkündür. Örneğin, emülgatör, plastik, fenolik reçine, ilaç, tekstil, patlayıcı, gübre, boya, deterjan, yapıştırıcı, tatlandırcı, kağıt, sabun, epoksi reçine, emprenye reçine ve ahşap koruyucu üretiminde ve kauçuk kimyasalları üretimi için katkı maddesi olarak sıklıkla kullanılır [5-7]. Bu endüstrilerin yanısıra, kömür dönüştürme işlemleri, kok firınları, petrol rafinerileri, herbisit üretimi, cam elyaf üretimi ve petrokimyasal üretimi gibi endüstrilerin atık sularındaki temel organik bileşiklerden biri de fenol olmaktadır [8-10].

Fenol giderim yöntemleri kirlilik derişimine göre üç temel gruba ayrilır [11, 12]: 1-Konsantre fenol atıkların arıtılması, 2Orta derece konsantre fenol atıkların arıtılması, 3-Seyreltik fenol atıkların arıtılması. Yüksek konsantrasyonda fenol içeren $(>500$ $\mathrm{mg} / \mathrm{L}$ ) atık suların arıtılması genelde uygun bir çözücü ile ekstraksiyon esasına dayanır ve \%98-99 oranında giderim sağlanabilir. Ancak, bu yüksek verimlilik değerlerinde bile, arıtma sonrasında, atık sularda belli miktarda fenol kalabilmektedir [12]. Orta dereceli kirliliği oluşturan 5-500 mg/L derişimli atık sularda en sık olarak biyolojik arıtma kullanılır ve fenol derişimi 0,5-1 ppm'e kadar düşürülebilir. Aktif karbon ile adsorpsiyon ve kimyasal oksidasyon da tercih edilen diğer yöntemlerdir. Atık suların fenol derişimi 1-0,1 ppm'in altında ise arıtma için aktif karbon kullanımı gibi fızikokimyasal ya da kimyasal metotlar tercih edilebilir. Bu arıtma işlemlerinin daha verimli olması için düşük $\mathrm{pH}$ değerlerinde çalışmak avantajlıdır [12].

Fenol giderimi için son y1llarda tercih edilen diğer bir metod da katalitik yaş oksidasyondur (KYO). KYO tepkimesinde, oksijen (hava), ozon, hidrojen peroksit veya bunların bir kombinasyonu oksitleyici olarak kullanılabilir. KYO metodu ile pek çok farklı organik kirletici, bir katalizör katkısı ile yüksek dönüşümle giderilebilir. KYO metodunda katalizörlerin kullanılması, oksidasyon tepkimesinin daha 1 lıml sıcaklık ve basınç koşullarında gerçeklemesini sağlar. $\mathrm{Bu}$ metodun bir diğer avantajı ise sadece tek bir kirleticinin veya benzer tür kirleticiler grubunun arıtımını sağlamasıdır [13].

Yaş katalitik oksidasyon tepkimelerinde destek malzemesi olarak sıklıkla kullanılan malzemelerden birisi de MCM-41'dir $[14,15]$. MCM-41 türü nano yapılı, mezogözenekli malzemeler, yaklaşık $1000 \mathrm{~m}^{2} / \mathrm{g}$ gibi geniş yüzey alanlarına ve yüksek termal, hidrotermal ve hidrolitik kararlılığa sahiptir. [16-20]. Yapıdaki kanalların duvarları amorf $\mathrm{SiO}_{2}$ 'dir ve gözeneklilik değerleri, toplam hacimlerinin \%80'i kadar yüksek olabilir [16, 21, 22]. Bu malzemeler, sentezlenirken gözeneklerin çap1, şablon molekülün uzunluğu değiştirilerek kontrol edilebilir. Ayrıca sentez koşulları esnektir yani farklı silika kaynakları (kolloidal silika, TEOS), farklı şablon malzeme (Heksadesilamin, CTMABr), farklı katkı maddeleri (örn. 1,3,5-trimetilbenzen) veya farklı reaksiyon koşulları (çözücü, sıcaklık, hidrotermal sentez süresi, reaktif mol oranı ve ortamın pH'sı) kullanıldığında farklı mezogözenekli sistemler üretilebilir. $\mathrm{Bu}$ değişiklikler aynı zamanda malzemelerin termal, hidrotermal ve mekanik kararlılıklarını da etkiler [16, 21-23].

Bu çalışma kapsamında Direkt Hidrotermal Sentez Metodu kullanılarak yüksek yüzey alanına sahip destek malzemesi MCM-41 ile, farklı Mn/Si molar oranlarına sahip Mn-MCM-41 katalizörleri sentezlenmiş ve XRD, BET, Parçacık Boyut Analizi, SEM ve EDS metotları ile karakterize edilmiştir. Karakterize edilen katalizörlerin aktiviteleri; farklı sıcaklıklarda ve atmosferik basınçta, atık su doğal pH'sında başlanılarak; 50 ppm model çözeltiler ve hidrojen peroksit içerikli KYO metodu kullanılarak kesikli reaktörde tespit edilmiştir.

\section{Materyal ve Metot}

\subsection{MCM-41 Katalizörünün Sentezi}

$\mathrm{Bu}$ çalışma kapsamında Direkt Hidrotermal Sentez Metodu kullanılarak MCM-41 destek malzemesi ve çözeltideki $\mathrm{Mn} / \mathrm{Si}$ molar yüzdesi $\% 20, \% 25$ ve $\% 30$ olan $(\mathrm{Mn} / \mathrm{Si}$ molar oranı 0,2 ; 0,25 ve 0,30 olan) üç farklı Mn-MCM-41 katalizörü sentezlenmiştir.

Sentezlerde silika kaynağı olarak sodyum silikat çözeltisi (27 wt $\% \mathrm{SiO}_{2}$ and $14 \mathrm{wt} \% \mathrm{NaOH}$, Aldrich) ve TEOS (\%98, Merck), yüzey aktif madde (şablon malzeme) olarak Setil Trimetil Amonyum Bromür (CTMABr, \%99, Merck), mineralleştirici olarak Hidroklorik Asit ( $\mathrm{HCl})$ (4 N çözelti, Laboratuvarda hazırlanmıştır), $\mathrm{NaOH}$ (1 N, Merck), Amonyum Hidroksit (\%25, Merck) ve Etil Amin (\%66-72, Aldrich), oksitleyici olarak Hidrojen Peroksit (\%30, Merck), metal tuzu olarak Manganez (II) Klorür Tetrahidrat $\left(\mathrm{MnCl}_{2} \cdot 4 \mathrm{H}_{2} \mathrm{O}\right.$, Merck) ve çözelti ortamı olarak deiyonize su kullanılmıştır.

Şekil 1'de görsel olarak özetlenen reçete, Doğrudan Hidrotermal Sentez Metodu ile MCM-41 destek malzemesini elde etmek için kullanılan, jelleşme, yıkama, kurutma ve kalsinasyon basamakları literatürden farklı olarak modifiye edilmiş olan sentez reçetesidir [24] ve aşağıdaki basamakları içermektedir:

1.26,4 gram yüzey aktif madde/şablon malzeme $150 \mathrm{ml}$ deiyonize su içinde sürekli karıştırma eşliğinde $28^{\circ} \mathrm{C}$ 'de çözülür.

2. Yüzey aktif madde çözeltisi hazırlandıktan sonra, bu çözeltiye 


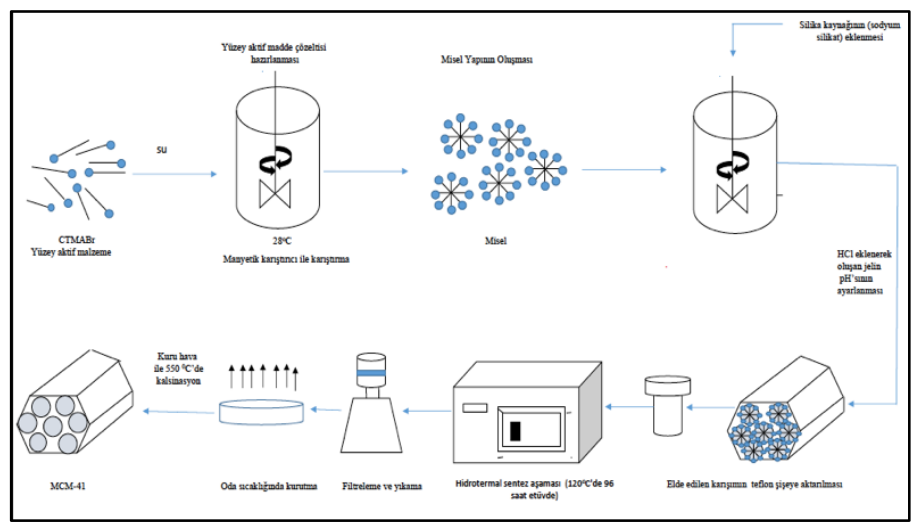

Şekil 1. MCM-41 katalizörünün sentez aşamaları

damla damla, sürekli karıştırma eşliğinde 22,6 ml sodyum silikat çözeltisi eklenir.

3.Çözeltinin pH'sı ölçülür, MCM-41 yapısının başarıyla elde edilmesi için optimum $\mathrm{pH}$ değeri 11 olmalıdır. Eğer çözelti pH's1 11'den fazla ise $4 \mathrm{~N} \mathrm{HCl}, 11$ 'den az ise $1 \mathrm{M} \mathrm{NaOH}$, sürekli karıştırma eşliğinde, damla damla, $\mathrm{pH}$ değeri 11,0 olana dek çözeltiye eklenir.

4.pH değeri 11 'e ayarlandıktan sonra oluşan jel bir saat daha $28^{\circ} \mathrm{C}$ 'de karıştırılır ve teflon şişe içinde $120^{\circ} \mathrm{C}$ 'ye 1 șitılmış etüve konur.

5.Hidrotermal sentez basamağ iç̧in teflon şişedeki jel 72 saat $120^{\circ} \mathrm{C}$ 'de bekletilir.

6.Etüvden elde edilen katı ürün vakum altında filtre edilir ve safsızlıkların giderimi için üründen geçen yıkama suyunun pH'sı 7,0 olana kadar yıkanır.

7.Katı ürün oda sıcaklığında 72 saat bekletilerek kurutulur.

8.Son olarak, katı ürün ortasında kuvars membran olan kuvars bir tüpte, $1 \mathrm{~L} / \mathrm{dk}^{\prime} l 1 \mathrm{k}$ kuru hava akışı altında, oda sıcaklığından $550^{\circ} \mathrm{C}^{\prime}$ ye $1{ }^{\circ} \mathrm{C} / \mathrm{dk}$ hizla isitilarak ve $550^{\circ} \mathrm{C}$ 'de 6 saat bekletilerek kalsine edilir.

\subsection{Mn-MCM-41 Katalizörlerinin Sentezi}

Şekil 2'de görsel olarak özetlenen reçete 25-Mn-MCM-41 katalizörünün jelleşme, yıkama, kurutma ve kalsinasyon basamakları literatürden farklı olarak modifiye edilmiş sentez reçetesidir ve aşağıdaki basamakları içermektedir [25, 26]:

1.Bir Teflon beherde, $0,2 \mathrm{~g} \mathrm{MnCl}_{2}-4 \mathrm{H}_{2} \mathrm{O}$ tuzu $5 \mathrm{~mL}$ deiyonize suda çözülür.

2.Bu çözeltiye sırasıyla silika kaynağı olarak 8,96 ml TEOS ve yüzey aktif malzeme olarak 2,9 g CTMABr sürekli karıştırma eşliğinde eklenir.

3. İkinci basamaktaki çözeltiye sırasıyla $1,33 \mathrm{ml}$ etilamin ve $1 \mathrm{~g}$ amonyum hidroksit sürekli karıştırma eşliğinde eklenir.

4.Sentez tepkimelerinin tamamlanması için elde edilen jel oda sıcaklığında 4 saat daha karıştırılır.

5.Dört saat sonunda elde edilen homojen jel teflon şişeye 5.Dört saat sonunda elde edilen homojen jel teflon şişeye transfer edilir ve hidrotermal sentez aşaması için $100{ }^{\circ} \mathrm{C}$ 'deki etüvde 48 saat bekletilir.

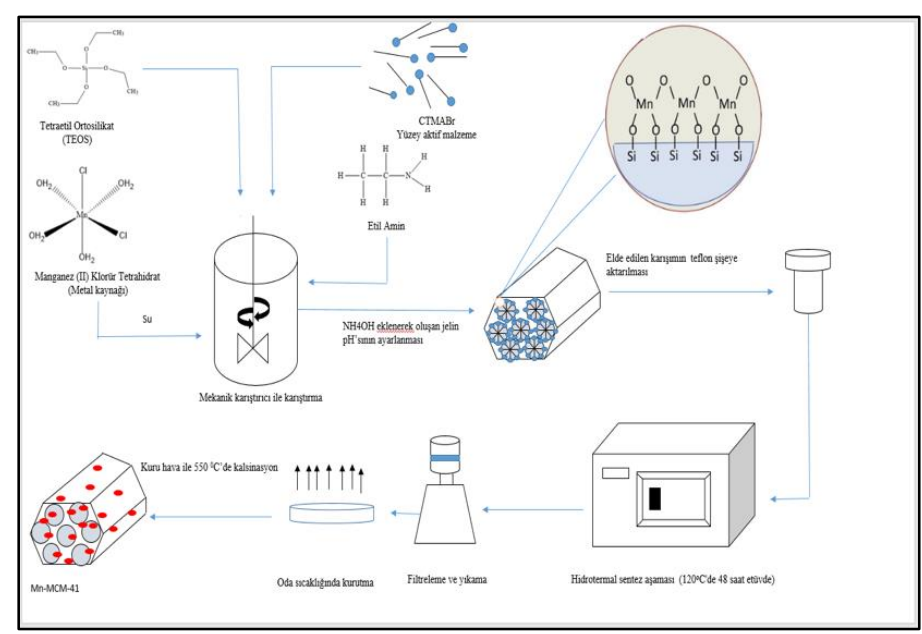

Şekil 2. Mn-MCM-41 katalizörlerinin sentez aşamaları

6.Hidrotermal sentez aşaması sona erdiğinde teflon şişeden alınan ürün filtre edilir ve deiyonize su ile katalizörden geçen suyun pH's1 7,00 olana dek yıkanır.

7.Kurutma işlemi için malzeme oda sıcaklığınde 3 gün bekletilir.

8.Son olarak, katı ürün ortasında kuvars membran olan kuvars bir tüpte, $1 \mathrm{~L} / \mathrm{dk}$ 'lık kuru hava akışı altında, oda sıcaklığından $550^{\circ} \mathrm{C}^{\prime}$ ye $1^{\circ} \mathrm{C} / \mathrm{dk}$ hizla isitılarak ve $550^{\circ} \mathrm{C}$ 'de 6 saat bekletilerek kalsine edilir

Çalışma kapsamında, çözeltideki Mn/Si molar oranı 0,20 (molar yüzde oranı \%20) olarak sentezlenen katalizör 20-MnMCM-41, 0,25 (molar yüzde oranı \%25) olarak sentezlenen katalizör 25- Mn-MCM-41 ve 0,30 (molar yüzde oranı \%30) olarak sentezlenen katalizör 30-Mn-MCM-41 olarak adlandırılmıştır.

\subsection{Karakterizasyon Teknikleri}

Sentezlenen katalizörlerin XRD desenleri 2 $\theta=2-10^{\circ}$ aralığında, $30 \mathrm{~mA}$ ve $40 \mathrm{kV}$ akım ve voltaj değerlerinde, $\mathrm{Cu} \mathrm{K \alpha}$ radyasyonu $(\lambda=0.15406 \mathrm{~nm})$ kullanılarak Bruker AXS D-8 Advance Difraktometresi ile elde edilmiştir. Azot adsorpsiyonu ve BET analizleri Micromeritics ASAP 2020 cihazında, sıvı azot sıcaklığında gerçekleştirilmiştir. Parçacık boyutu ve parçacık boyut dağılımı analizleri için Mastersizer 2000 cihazı kullanılmıştır. SEM görüntüleri SE2 Analitik Görüntüleme Sistemi ile donatılmış ZEISS SUPRA Taramalı Elektron Mikroskobu'nda elde edilmiştir. Analizler 20 kV'da 8-48 mm çalışma mesafelerinde gerçekleştirilmiştir. EDS analizleri de aynı cihazda gerçekleştirilmiştir.

\subsection{Deney Sistemi}

Katı fenol ve deiyonize su kullanılarak laboratuar ortamında 50 ppm'lik sentetik fenol çözeltileri hazırlanmıştır. MCM-41 ve Mn-MCM-41 katalizörleri eşliğinde, hidrojen peroksit içerikli KYO yöntemi ile fenol giderimi, kesikli reaktör olarak kullanılan 250 ml'lik bir beherde, 25,40 ve $60^{\circ} \mathrm{C}^{\prime} \mathrm{de}$ gerçekleştirilmiştir. $\mathrm{Bu}$ amaçla, öncelikle, 0,15 g katalizör numunesi, sürekli karıştırma altında, 150 mL'lik 50 ppm'lik fenol çözeltisine eklenmiştir. Daha sonra oluşan çözeltiye 2 $\mathrm{mL} /$ dakika hızla $0,1 \mathrm{~mol} / \mathrm{L} \mathrm{H}_{2} \mathrm{O}_{2}$ çözeltisi (toplam $67 \mathrm{~mL}$ ) damla damla ilave edilmiştir. Otuz dakika aralıklar ile reaktörlerden 7 $\mathrm{mL}$ örnekler alınmış ve $0,22 \mu \mathrm{m}$ naylon filtre kullanılarak filtre 
edilmiştir. Filtre edilen örneklerin fenol derişimleri, $270 \mathrm{~nm}$ dalga boyunda, önceden kalibre edilmiş Perkin-Elmer Lambda 35 UV-VIS Spektrofotometresi ile ölçülmüştür. Deney ve filtrasyon sistemleri Şekil 2 ve Şekil 3 'te verilmiştir.

Deney çözeltilerinden toplam sekiz numune alınmıştır ve alınan numunelerin çözelti hacmini ve herhangibir andaki kirlilik derişimini etkilememesi için aynı anda dört deney seti ile çalışılmış ve her deney setinden sadece iki örnek alınarak hacim değişiminden gelecek hatanın \%5’ten az olması sağlanmıştır.

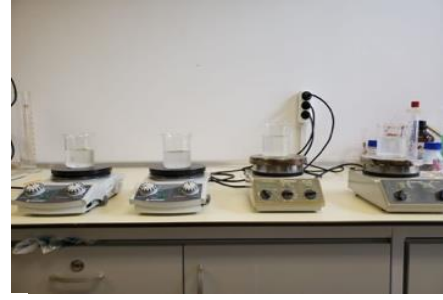

Şekil 2. Fenol giderim sistemi

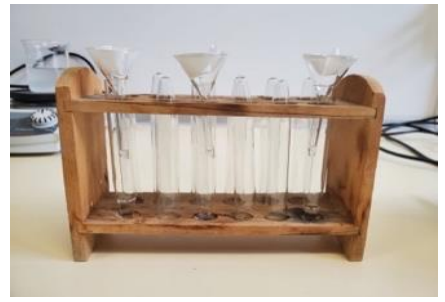

Şekil 3. Reaktörlerden alınan örneklerin filtrasyonu

\section{Araştırma Sonuçları ve Tartışma}

\subsection{Karakterizasyon Bulguları}

Şekil 4’te MCM-41 katalizörünün XRD grafiği verilmiştir. Literatür incelendiğinde sentezlenen tipik MCM-41 XRD desenlerinin $2,5^{\circ}, 4,0^{\circ}$ ve $5,0^{\circ}$ civarında üç pik verildiği görülmektedir [27]. $\mathrm{Bu}$ çalışmada sentezlenen MCM-41 katalizörü için de $2 \theta=2,54^{\circ}$ açısında keskin bir pik, $2 \theta=4,38$ ve $5,12^{\circ}$ açılarında ise ikincil piklerin gözlenmesi katalizörün hekzagonal MCM-41 yapısında olduğunu göstermektedir [16, 17].

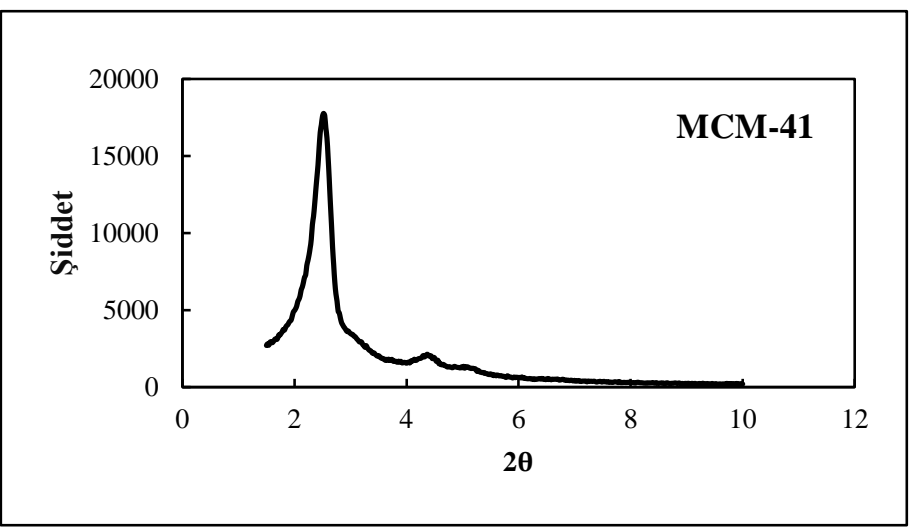

Şekil 4. MCM-41 katalizörünün XRD deseni

Manganez metali yüklenmiş MCM-41 katalizörlerinin düşük açılardaki XRD desenleri incelendiğinde (örnek olarak Şekil 5.a'da 25-Mn-MCM-41 katalizörünün düşük açılardaki XRD deseni verilmiştir) ise metal eklemenin MCM-41 yapısını bozduğu ve düzenli kristal yapıya işaret eden ana ve ikincil piklerin elde edilemediği görülmüştür. Yüksek açılarda ise, Şekil 5.b'de görüldüğü gibi, $31-32^{\circ}$ civarında $\mathrm{Mn}$ metaline tekabül eden bir pikin olması metalin yapıya başarıyla eklendiğini göstermektedir.

Azot adsorpsiyon/desorpsiyonu ve parçacık boyut analizi sonrasında elde edilen parçacık boyutları ve BET yüzey alanı değerleri Tablo 1'de verilmiştir. Literatürde MCM-41 türü

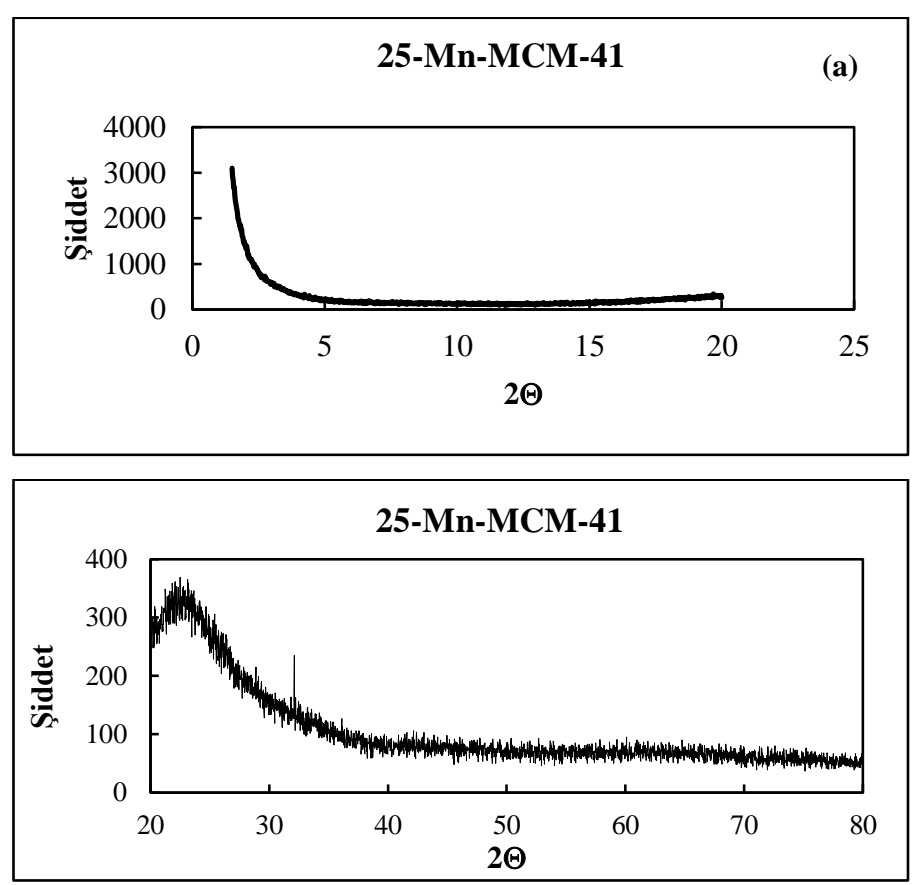

Şekil 5. 25-Mn-MCM-41 katalizörünün (a) 2-20 arasindaki XRD deseni (b) 20-80 $\mathrm{C}$ arasindaki XRD deseni

katalizörler için yapılan parçacık boyut analizleri incelendiğinde, genelde elde edilen ürünlerin parçacık boyutlarının $2 \mu$ m'den düşük olduğu ve (SEM fotoğraflarından) parçacıkların kümeleştiği görülmüştür. $\mathrm{Bu}$ nedenle Tablo 1'deki parçacık boyutlarının $17 \mu$ m'den fazla olması, parçacıkların kümeleşip aglomerler oluşturduğunu göstermektedir [25, 28, 29].

Tablo 1. Katalizörlerin Fizikokimyasal Özellikleri

\begin{tabular}{c|c|c|c}
\hline Katalizör & $\begin{array}{c}\text { EDS } \\
\text { Mn/Si Molar } \\
\text { Oranı }\end{array}$ & $\begin{array}{c}\text { Parçacık } \\
\text { boyutu }(\boldsymbol{\mu m})\end{array}$ & $\begin{array}{c}\text { BET } \\
\left(\mathbf{m}^{2} / \mathbf{g}\right)\end{array}$ \\
\hline MCM-41 & - & 25,6 & 1187 \\
\hline 20-Mn-MCM-41 & 0,062 & 35,2 & 335 \\
\hline 25-Mn-MCM-41 & 0,060 & 17,6 & 225 \\
\hline 30-Mn-MCM-41 & 0,071 & 44,8 & 291 \\
\hline
\end{tabular}

Tablo 1 incelendiğinde, 20-MCM-41 ve 25-MCM-41 katalizörleri için çözeltideki Mn/Si molar oranları sırası ile 0,20 ve 0,25 olmasına rağmen, EDS analizi ile ölçülen $\mathrm{Mn} / \mathrm{Si}$ molar oranları sırası ile 0,062 ve 0,060 şeklindedir. EDS metodu malzemelerin yüzeye yakın derinliklerindeki atom miktarlarını tespit eden bir analiz tekniğidir ancak tepkimeler de genellikle difüzyon kısıtlamaları nedeni ile yüzeye yakın bölgelerde gerçekleştiği için katalizördeki Metal/Si oranı hakkında önemli bilgi vermektedir. Tablo 1'de görüldüğü gibi 20-MCM-41 ve 25MCM-41 katalizörleri için yüzeyde metal yükleme oranları nerdeyse eşit bulunmuştur. Metal yüklü katalizörlerin yüksek açı XRD desenleri Şekil 6'da, tüm katalizörlerin SEM fotoğrafları ise Şekil 7'de verilmiştir. Şekil 6 ve Tablo 1 birlikte incelendiğinde, 20-Mn-MCM-41 ve 30-Mn-MCM-41 katalizörlerinin metal yükleme oranlarının, ortalama parçacık 
boyutlarının, BET yüzey alanlarının ve $31-32^{\circ}$ civarında, Mn metaline tekabül eden piklerinin 25-Mn-MCM-41 katalizörüne oranla daha yüksek/şiddetli olduğu görülmektedir. 20-MnMCM-41 katalizörü ile 30-Mn-MCM-41 katalizörü kendi içinde karşılaştırıldığında ise metal yükleme oranı arttıkça Mn metaline tekabül eden XRD piki şiddetinin ve katalizör parçacık boyutunun arttığı, BET yüzey alanının ise düştüğü görülmektedir. Son olarak, Şekil 7.b. ve Şekil 7.c karşılaştırıldığında, 25-Mn-MCM-41 katalizörüne oranla 20-MnMCM-41 katalizöründe daha çok aglomerleşme olduğu ve parçacık boyutunun daha büyük olduğu görülmektedir. Bütün bu bulgular birlikte değerlendirildiğinde, şu sonuçlara varılmaktadır: Metal yüklü tüm katalizörler için yüklenen Mn metalinin bir kısmı katalizörün dış yüzeyine yüklenmiş ve bu metal kümeleri XRD analizinde $31-32^{\circ}$ civarında pikler olarak elde edilmiştir (30-Mn-MCM-41 katalizörü için $78^{\circ}$ civarında bir de $\mathrm{Mn}_{2} \mathrm{O}_{3}$ fazına tekabül eden XRD piki elde edilmiştir) [30, 31]. EDS analizlerine göre yüzeyde 20-Mn-MCM-41 katalizörüne yüklenen metal miktarı, 25-Mn-MCM-41 katalizörüne oranla daha fazla olduğu için bu katalizörde Mn metaline tekabül eden XRD pik şiddeti de daha fazladır, daha fazla metal katalizörün dış yüzeyine adsorplanarak katalizör yapısını etkilemiş, daha fazla aglomerleşme olmuş ve daha büyük parçacıklar elde edilmiştir. 25-Mn-MCM-41 katalizörü için ise yapıya eklenen metalin bir kısmı katalizörün gözenek duvarları içine tutunarak gözenekleri kısmen bloke etmiş, toplam yüzey alanı etkilenmiş ve 20-Mn-MCM-41 katalizöründen

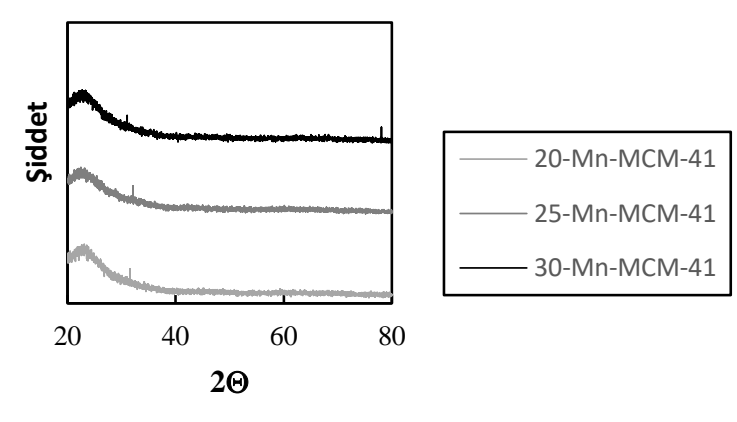

Şekil 6. Metal yüklü katalizörlerin 2-80 aralı̆̆ındaki XRD desenleri

daha düşük bir BET yüzey alanı değeri elde edilmiştir. Katalizörün dış yüzeyinde daha az metal adsorplandığı için Şekil 6'daki XRD pik şiddeti 20-Mn-MCM-41 katalizörüne oranla düşmüş ve Şekil 7.c'de görüldüğü gibi parçacıklar 20-MnMCM-41 katalizörlerine oranla daha az yapısal bozulma (aglomerleşme) göstermiştir.

\subsection{Reaksiyon Sonuçları}

Çalışma kapsamında, 50 ppm'lik fenol çözeltisi ile kesikli reaktörde, atmosferik basınçta, doğal tepkime pH'sında ve 500 rpm karıştırma hızında, 25,40 ve $60^{\circ} \mathrm{C}$ sıcaklıklarda elde edilen fenol giderim sonuçları Şekil 8 ve Tablo 2'de verilmiştir. Tablo 2'deki değerler Eşitlik (1) kullanılarak elde edilmiştir. Eşitlik 1 'de $\mathrm{C}_{\mathrm{o}}$ atıksuyun ilk derişimine yani 50 ppm'e $(\mathrm{mg} / \mathrm{L}), \mathrm{C}(\mathrm{t})$ ise $30 \mathrm{dk}$ aralıklarla reaktörden alınıp filtre edilerek önceden kalibre edilmiş UV-VIS Spektrofotometresinde okunan fenol derişimlerine tekabül etmektedir:
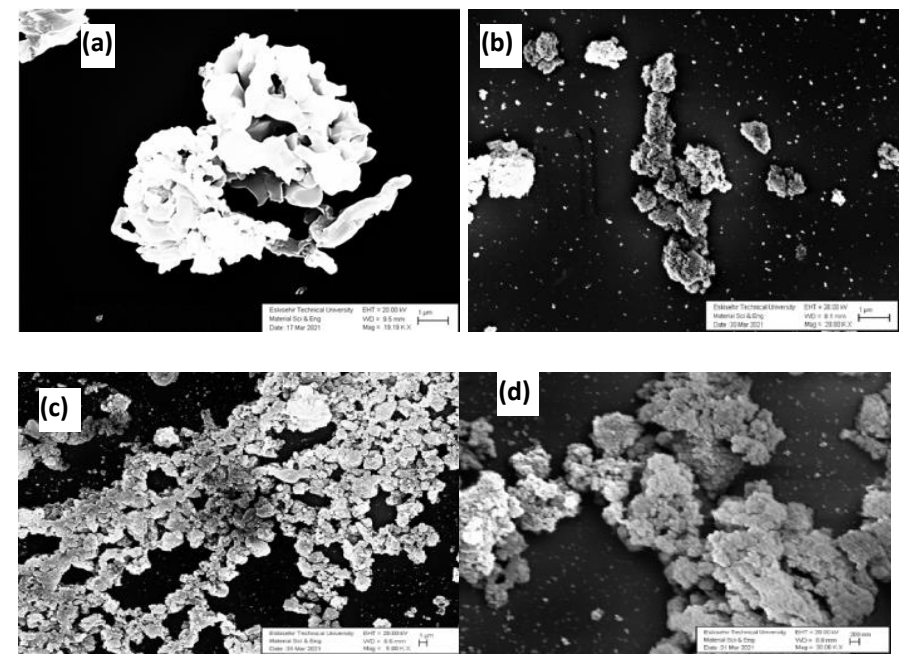

Şekil 7. (a) MCM-41 (b) 20-Mn-MCM-41 (c) 25-Mn-MCM-41

(d) 30-Mn-MCM-41 katalizörleri için SEM fotoğrafları

$$
\% \text { Fenol Giderimi }=\frac{C_{o}-C(t)}{C_{o}} * 100
$$

Şekil 8'de görüldüğü gibi, tüm katalizörler için, sıcaklıkla birlikte fenol giderimi artmıştır. $25^{\circ} \mathrm{C}$ 'de katalizörler arasında belirgin bir aktivite farkı görülmemiştir ancak hem 40 hem de $60^{\circ} \mathrm{C}$ 'de en iyi fenol giderimi EDS analizine göre yüzeyde $\mathrm{Mn} / \mathrm{Si}$ molar oranı 0,06 olan 25-Mn-MCM-41 katalizörü tarafından sağlanmıştır.

$25^{\circ} \mathrm{C}$ 'de, 20-Mn-MCM-41，25-Mn-MCM-41 ve 30-MnMCM-41 katalizörleri için fenol giderim değerlerinin sırasıyla $\% 45,4, \% 45,2$ ve 45,8 olarak birbirine çok yakın elde edildiği ve üç katalizörün de 150 dakika sonrasında yaklaşık maksimum giderim değerine ulaştığ 1 görülmüştür. $40^{\circ} \mathrm{C}$ 'de daha farklı bir trend gözlenmiştir. 25-Mn-MCM-41 katalizörü 180 dakika sonrasında maksimum verim değerine yaklaşırken, diğer katalizörler stabil duruma gelememiştir. Son olarak, $60{ }^{\circ} \mathrm{C}$ 'de, 20-Mn-MCM-41， 25-Mn-MCM-41 ve 30-Mn-MCM-41 katalizörleri için fenol giderim yüzdeleri sırasıyla \%54,8, \%56 ve \%54,5 olarak elde edilmiştir. 25-Mn-MCM-41 katalizörü 120 dakika sonrasında maksimum verim değerine yaklaşırken, diğer katalizörler stabil bir trend göstermemiştir. 40 ve $60^{\circ} \mathrm{C}$ 'de en iyi giderim performansını 25-Mn-MCM-41 katalizörü sağladığ için, çalışmada optimum $\mathrm{Mn} / \mathrm{Si}$ molar yükleme oranı 0,060 (EDS sonucu) olarak belirlenmiştir.

Literatürdeki fenol giderim çalışmaları incelendiğinde, sadece adsorpisyon metodu kullanılan kimi çalışmalarda "kalsine edilmemiş" katalizörlerin "kalsine edilmiş" katalizörlerden daha yüksek fenol giderimi sağladığı görülmüştür. Bunun nedeni, yapı içinde kalan yüzey aktif malzemenin hidrofobik özelliği ve fenol grubu ile olumlu etkileşimidir [32]. Tablo 2'de 25,40 ve $60^{\circ} \mathrm{C}$ sicaklıklarda MCM-41-KE (Kalsine edilmemiş MCM-41), MCM-41 (Kalsine edilmiş MCM-41) ve metal yüklü katalizörler için elde edilen fenol giderim sonuçları verilmiştir. $\mathrm{Bu}$ sonuçlar adsorpsiyon mekanizmasının KYO tepkimesi yanında baskın olmadığını ve MCM-41 yapısına metal eklemenin reaksiyon verimini önemli ölçüde artırdığını göstermektedir. 
$\mathrm{Bu}$ çalışmada elde edilen sonuçlar benzer koşullardaki literatür çalışmaları ile karşılaştırılmış ve sonuçlar Tablo 3'de özetlenmiştir. Bu tabloya göre, 60 ppm başlangıç derişiminde, bakır içerikli SBA-15 katalizörü kullanıldığında, daha kısa sürede (60 dakikada) \%56 fenol giderimi elde edilmiştir; ancak deney düzeneğinde sürekli olarak $100 \mathrm{ml} / \mathrm{dk}$ azot sağlama gerekliliği olması sözü geçen çalışmanın maliyetini artıracaktır ve çalışmada sadece teorik metal yükleme oranı verilmiş olup, gerçek metal yükleme oranı ölçülmemiştir [33]. Aktif karbon destekli bakır katalizör ile yapılan çalışmada ise \%99,9 dönüşüm elde edilmiştir ancak metal yükleme oranı verilmemiştir ve daha yüksek basınçta (2 atm) çalışma gerekliliği ortaya çıkmıştır [34].
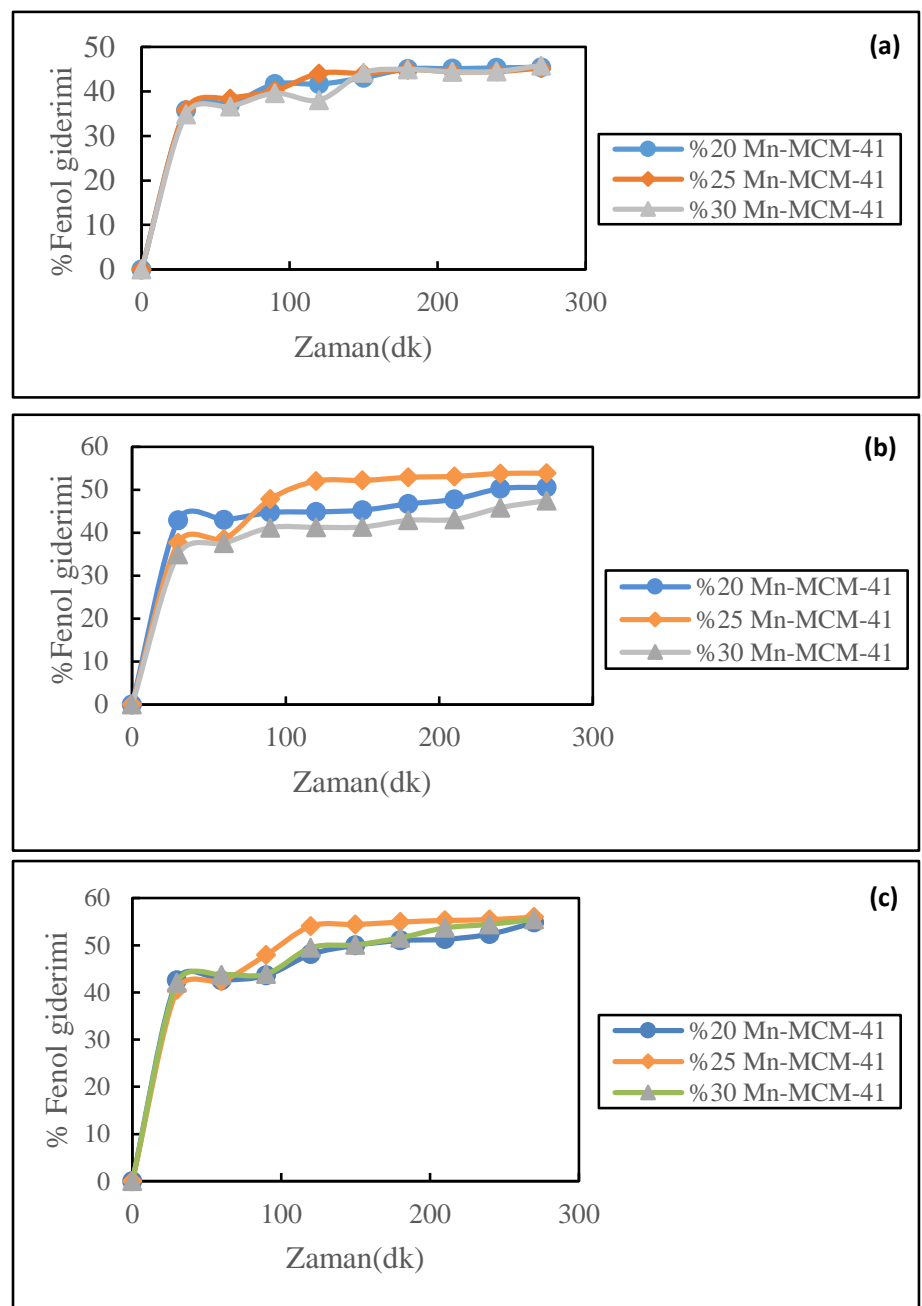

Şekil 8. Fenol giderim sonuçlart: (a) $25^{\circ} \mathrm{C}(\mathrm{b}) 40^{\circ} \mathrm{C}$ (c) $60^{\circ} \mathrm{C}$

\section{Sonuç}

$\mathrm{Bu}$ çalışma kapsamında, orta dereceli konsantre atık sulardan fenol giderimi için Direkt Hidrotermal Sentez Metodu ile üretilen MCM-41 ve Mn-MCM-41 türü katalizörler, atmosferik basınçta, 25,40 ve $60^{\circ} \mathrm{C}^{\prime} \mathrm{de}, 500 \mathrm{rpm}$ karıştırma hızında, kesikli reaktörde hidrojen peroksit katkılı yaş katalitik oksidasyon metodu kullanılarak test edilmiştir.

Kirlilik giderim deneylerinde, 1,0 g/L katalizör, dört kesikli reaktör kullanılmış, 4,5 saat süresince örnekleme yapılarak toplamda sekiz veri elde edilmiş ve örneklerin fenol derişimleri önceden kalibre edilmiş UV Görünür Spektrofotometresi ile tayin edilmiştir.
Tablo 2. Farklı Slcaklıklardaki Reaksiyon Bulguları

\begin{tabular}{c|c|c|c}
\hline & \multicolumn{3}{|c}{ \% Fenol Giderimi } \\
\hline Katalizör & $\mathbf{2 5}^{\circ} \boldsymbol{C}$ & $\mathbf{4 0}^{\circ} \boldsymbol{C}$ & $\mathbf{6 0}^{\circ} \boldsymbol{C}$ \\
\hline$M C M-41-K E$ & 9,8 & 18,3 & 21 \\
\hline$M C M-41$ & 40,6 & 41,0 & 41,6 \\
\hline $20-M n-M C M-41$ & 45,4 & 50,5 & 54,8 \\
\hline $25-M n-M C M-41$ & 45,2 & 53,8 & 56 \\
\hline $30-M n-M C M-41$ & 45,8 & 47,5 & 54,5 \\
\hline
\end{tabular}

Tablo 3. Bulguların literatür ile karşılaştırılması [33,34]

\begin{tabular}{|c|c|c|c|c|c|}
\hline Katalizör & $\begin{array}{c}\mathrm{Mn} / \mathrm{Si} \\
\text { molar } \\
\text { oranı }\end{array}$ & 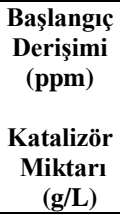 & $\begin{array}{c}\mathbf{T}\left({ }^{\circ} \mathrm{C}\right) \\
\mathbf{P}(\mathrm{atm})\end{array}$ & $\begin{array}{c}\text { Süre } \\
\text { (dk) }\end{array}$ & $\begin{array}{c}\% \\
\text { Fenol } \\
\text { Giderimi }\end{array}$ \\
\hline $\begin{array}{l}\text { 25-Mn- } \\
\text { MCM-41 }\end{array}$ & $\begin{array}{c}0,06 \\
\text { (EDS) } \\
\end{array}$ & $\begin{array}{l}50 \\
1,0 \\
\end{array}$ & $\begin{array}{c}60 \\
1 \\
\end{array}$ & 270 & 56 \\
\hline $\begin{array}{c}\text { Cu-SBA- } \\
15\end{array}$ & $\begin{array}{c}0,02 \\
\text { (Çözeltide) }\end{array}$ & $\begin{array}{l}60 \\
1,0\end{array}$ & $\begin{array}{c}60 \\
1 \\
(100 \\
\mathrm{ml} / \mathrm{dk} \text { azot } \\
\text { akımı ile })\end{array}$ & 60 & 56 \\
\hline $\begin{array}{c}\text { Aktif } \\
\text { karbon } \\
\text { destekli } \\
\text { bakir } \\
\text { katalizör }\end{array}$ & - & $\begin{array}{l}60 \\
1,0\end{array}$ & $\begin{array}{l}38 \\
2\end{array}$ & 360 & 99,9 \\
\hline
\end{tabular}

Deneylerde kalsine edilmemiş MCM-41 destek malzemesi, kalsine edilmiş MCM-41 destek malzemesi ve sentez reçetelerine göre çözeltideki $\mathrm{Mn} / \mathrm{Si}$ molar oranı sırasıyla 0,20 ; 0,25 ve 0,30 olan Mn-MCM-41 türü katalizörler kullanılmıştır. Ancak, EDS sonuçları göstermiştir ki katalizörlere sentez reçetesinde hesaplanan oranda metal yüklenememiş ve katalizör yüzeyinde gerçek $\mathrm{Mn} / \mathrm{Si}$ oranları, 20-Mn-MCM-41 katalizörü için 0,062, 25-Mn-MCM-41 katalizörü için 0,060 ve 30-MnMCM-41 için 0,071 olarak tayin edilmiştir.

Fenol giderimi tüm katalizörler için sıcaklıkla artmıştır. Çalışılan tüm sıcaklıklarda kalsine edilmiş MCM-41 katalizörü, kalsine edilmemiş MCM-41-KE katalizöründen daha yüksek giderim sağlamıştır; bu da çalışmada, yaş katalitik oksidasyon tepkimesinin yanında adsorpsiyon mekanizmasının baskın olmadığını göstermiştir.

Yapıya metal eklenmesi, çalışılan tüm sıcaklıklarda, fenol giderimini artırmıştır ve optimum fenol giderimi, $60^{\circ} \mathrm{C}$ 'de, 25 Mn-MCM-41 katalizörü ile \%56 olarak hesaplanmıştır

Mn-MCM-41 türü katalizörler ile 0,06 gibi düşük bir metal yükleme oranında $(\mathrm{Mn} / \mathrm{Si}$ molar oranı), 1lımlı tepkime koşullarında $\left(60^{\circ} \mathrm{C}\right.$ ve atmosferik basınç), kesikli reaktörde, $\mathrm{H}_{2} \mathrm{O}_{2}$ içerikli Katalitik Islak Oksidasyon Yöntemi ile, \%50'nin üzerinde (\%56) fenol giderimi sağlanması, orta dereceli konsantre fenol atıksularının arıtılmasında literatüre önemli bir katk1 olacaktır.

\section{Teşekkür}

$\mathrm{Bu}$ çalışma, Anadolu Üniversitesi Bilimsel Araştırma Projeleri kapsamında, BAP 1003F97 ve BAP 1106F120 No'lu Projeleri ile desteklenmiştir. 


\section{Kaynakça}

1.Ganbold, B. (2005). Aktif karbon ve iyon değiştiriciler kullanılarak sudan fenol giderilmesi (Yayımlanmamış Yüksek Lisans Tezi). Yıldız Teknik Üniversitesi, Fen Bilimleri Enstitüsü. http://dspace.yildiz.edu.tr/xmlui/handle/1/5076.

2.Adar, E., Atay, P. N., Büncü, K., \& Bilgili, M. S. (2020). Phenol removal from synthetic wastewater with powdered activated carbon: Isotherms, kinetics and thermodynamics. Environmental Research and Technology, 3(1). https://doi.org/10.35208/ert.692302.

3.Singh, A. (2013). Assessment of Bioremediation of oil and phenol contents in refinery waste water via bacterial consortium. Journal of Petroleum \& Environmental Biotechnology, 04(03). https://doi.org/10.4172/21577463.1000145 .

4.Babich, H., \& Davis, D. (1981). Phenol: A review of environmental and health risks. Regulatory Toxicology and Pharmacology, 1(1), 90-109. https://doi.org/10.1016/02732300(81)90071-4.

5.Arpe, H.-J. (2007). Industrielle organische chemie: bedeutende vor- und zwischenprodukte, sechste, vollständig überarbeitete auflage. WILEY-VCH.

6.Abdollahi, M., \& Hassani, S. (2014). Phenol. In M. Derakhshani \& P. Wexler (Eds.), Encyclopedia of Toxicology (3rd ed., pp. 871-873). Academic Press.

7.Exon, J. H. (1984). A review of chlorinated phenols. Veterinary and Human Toxicology, 26(6), 508-520.

8.Veeresh, G. S., Kumar, P., \& Mehrotra, I. (2005). Treatment of phenol and cresols in upflow anaerobic sludge blanket (UASB) process: a review. Water Research, 39(1), 154-170. https://doi.org/10.1016/j.watres.2004.07.028.

9.Jadhav, D. N., \& Vanjara, A. K. (2004). Removal of phenol from wastewater using sawdust, polymerized sawdust and sawdust carbon. Indian Journal of Chemical Technology, $11(1), 35-41$.

10.Parsons, W. A. (1965). Chemical treatment of sewage and industrial wastes. National Lime Association.

11.Saravanan, P., Pakshirajan, K., \& Saha, P. (2008). Growth kinetics of an indigenous mixed microbial consortium during phenol degradation in a batch reactor. Bioresource Technology, 99(1), 205-209. https://doi.org/10.1016/j.biortech.2006.11.045.

12.Patterson, J. W. (1975). Wastewater treatment technology (1st ed.). Ann Arbor Science.

13.Gomes, H., Selvam, P., Dapurkar, S., Figueiredo, J., \& Faria, J. (2005). Transition metal $(\mathrm{Cu}, \mathrm{Cr}$, and V) modified MCM41 for the catalytic wet air oxidation of aniline. Microporous and Mesoporous Materials, 86(1-3), 287-294. https://doi.org/10.1016/j.micromeso.2005.07.022.

14.Wu, Q., Hu, X., Yue, P. L., Zhao, X. S., \& Lu, G. Q. (2001). Copper/MCM-41 as catalyst for the wet oxidation of phenol. Applied Catalysis B: Environmental, 32(3), 151-156. https://doi.org/10.1016/s0926-3373(01)00131-x.

15.Gomes, H., Selvam, P., Dapurkar, S., Figueiredo, J., \& Faria, J. (2005). Transition metal $(\mathrm{Cu}, \mathrm{Cr}$, and V) modified MCM41 for the catalytic wet air oxidation of aniline. Microporous and Mesoporous Materials, 86(1-3), 287-294. https://doi.org/10.1016/j.micromeso.2005.07.022.

16.Verweij, H. J. (2003). Ceramic membranes: morphology and transport. Journal of Materials Science, 38, 4677-4695.
17.Rouquerol, J., Avnir, D., Fairbridge, C. W., Everett, D. H., Haynes, J. M., Pernicone, N., Ramsay, J. D. F., Sing, K. S. W., \& Unger, K. K. (1994). Recommendations for the characterization of porous solids (Technical Report). Pure and Applied Chemistry, 66(8), 1739-1758. https://doi.org/10.1351/pac199466081739.

18.Kresge, C. T., Leonowicz, M. E., Roth, W. J., Vartuli, J. C., \& Beck, J. S. (1992). Ordered mesoporous molecular sieves synthesized by a liquid-crystal template mechanism. Nature, 359(6397), 710-712. https://doi.org/10.1038/359710a0.

19.Beck, J. S., Vartuli, J. C., Roth, W. J., Leonowicz, M. E., Kresge, C. T., Schmitt, K. D., Chu, C. T. W., Olson, D. H., Sheppard, E. W., McCullen, S. B., Higgins, J. B., \& Schlenker, J. L. (1992). A new family of mesoporous molecular sieves prepared with liquid crystal templates. Journal of the American Chemical Society, 114(27), 1083410843. https://doi.org/10.1021/ja00053a020.

20.Yang, X., Zhang, S., Qiu, Z., Tian, G., Feng, Y., \& Xiao, F. S. (2004). Stable Ordered Mesoporous Silica Materials Templated by High-Temperature Stable Surfactant Micelle in Alkaline Media. The Journal of Physical Chemistry B, 108(15), 4696-4700. https://doi.org/10.1021/jp0380226.

21.Jiang, T., Shen, W., Tang, Y., Zhao, Q., Li, M., \& Yin, H. (2008). Stability and characterization of mesoporous molecular sieve using natural clay as a raw material obtained by microwave irradiation. Applied Surface Science, 254(15), 4797-4802. https://doi.org/10.1016/j.apsusc.2008.01.138.

22.Alothman, Z. A., \& Apblett, A. W. (2010a). Metal ion adsorption using polyamine-functionalized mesoporous materials prepared from bromopropyl-functionalized mesoporous silica. Journal of Hazardous Materials, 182(13), 581-590. https://doi.org/10.1016/j.jhazmat.2010.06.072.

23.Vallet-Regí, M., Balas, F., \& Arcos, D. (2007). Mesoporous materials for drug delivery. Angewandte Chemie (Internation Ed. in English), 46(40), 7548-7558. https://doi.org/10.1002/anie.200604488.

24.Zhang, Q., Wang, Y., Ohishi, Y., Shishido, T., \& Takehira, K. (2001). Vanadium-Containing MCM-41 for Partial Oxidation of Lower Alkanes. Journal of Catalysis, 202(2), 308-318. https://doi.org/10.1006/jcat.2001.3276.

25.Büchel, G., Grün, M., Unger, K. K., Matsumoto, A., \& Kazuo, T. (1998). Tailored syntheses of nanostructured silicas: Control of particle morphology, particle size and pore size. Supramolecular Science, 5(3-4), 253-259. https://doi.org/10.1016/s0968-5677(98)00016-9.

26.Shao, Y., Wang, X., Kang, Y., Shu, Y., Sun, Q., \& Li, L. (2014). Application of Mn/MCM-41 as an adsorbent to remove methyl blue from aqueous solution. Journal of Colloid Interface Science, 429, 25-33. https://doi.org/10.1016/j.jcis.2014.05.004.

27.AlOthman, Z., \& Apblett, A. W. (2009). Synthesis of mesoporous silica grafted with 3glycidoxypropyltrimethoxy-silane. Materials Letters, 63(27), 2331-2334. https://doi.org/10.1016/j.matlet.2009.07.067.

28.Grün, M., Lauer, I., \& Unger, K. K. (1997). The synthesis of micrometer- and submicrometer-size spheres of ordered mesoporous oxide MCM-41. Advanced Materials, 9(3), 254-257. https://doi.org/10.1002/adma.19970090317.

29.Unger, K., Kumar, D., Grün, M., Büchel, G., Lüdtke, S., Adam, T., Schumacher, K., \& Renker, S. (2000). Synthesis of spherical porous silicas in the micron and submicron size 
range: challenges and opportunities for miniaturized highresolution chromatographic and electrokinetic separations. Journal of Chromatography A, 892(1-2), 47-55. https://doi.org/10.1016/s0021-9673(00)00177-1.

30.Lin, C.-C., Lin, L.-M., Chang, C.-T., Chiou, C.-S., \& Ma, C. M. (2010, July). Study on the Conversion of Methane into $\mathrm{CO} 2$ and Performance Assessment with Mesoporous Catalyst at Low Temperature. 103 rd A\&WMA's Annual Conference and Exhibition, Alberta, Canada.

31.Rakitskaya, T., Truba, A., Dzhyga, G., Nagaevs'ka, A., \& Volkova, V. (2018). Water Vapor Adsorption by Some Manganese Oxide Forms. Colloids and Interfaces, 2(4), 61. https://doi.org/10.3390/colloids2040061.

32.Mangrulkar, P. A., Kamble, S. P., Meshram, J., \& Rayalu, S. S. (2008). Adsorption of phenol and o-chlorophenol by mesoporous MCM-41. Journal of Hazardous Materials, 160(2-3), 414-421. https://doi.org/10.1016/j.jhazmat.2008.03.013.

33.Akti, F., \& Balci, S. (2019). Structural Variations in SBA-15 by Copper Incorporation and a Test in Catalytic Wet Peroxide Oxidation of Phenol. Structural Variations in SBA15 by Copper Incorporation and a Test in Catalytic Wet Peroxide Oxidation of Phenol, 31, 91-102.

34.Britto, J. M., Oliveira, S. B. D., Rabelo, D., \& Rangel, M. D. C. (2008). Catalytic wet peroxide oxidation of phenol from industrial wastewater on activated carbon. Catalysis Today, 133-135,

582-587.

https://doi.org/10.1016/j.cattod.2007.12.112. 